\title{
Visual Molecular Dynamics Investigations of the Impact of Hydrophobic Nanoparticles on Prognosis of Alzheimer's Disease and Cancers
}

\author{
I.C. Baianu*, M. Charles and V.I. Prisecaru \\ *University of Illinois at Urbana, ACES College, \\ FSHN, Agricultural \& Food Chemistry NMR \& NIR Microspectroscopy Facility, \\ 350 Burnsides research Laboratory, 1208 Pennsylvania Ave, Urbana, IL. 61801, USA \\ email: i-baianu@uiuc.edu
}

[Preprint- 04/02/2012]

\begin{abstract}
The possible impact of hydrophobic lectin nanoparticles on the prognosis and progression of Alzheimer's disease (AD) and cancers was investigated by Visual Molecular Dynamics (VMD) computer modeling programs available from the Beckmann Advanced Research Institute at the University of Illinois at Urbana. Our results indicate the possibility of impeding pathological aggregation of certain proteins such as modified tau- or beta-amyloid that are currently being considered as possible causes of Alzheimer's disease. VMD programs serve as useful tools for investigation hydrophobic protein aggregation that may play a role in aging of human populations.

* Corresponding Author.
\end{abstract}

\section{KEY WORDS:}

Visual Molecular Dynamics (VMD) computer modeling applications in Nanomedicine; novel vaccines from plants; medical applications of Lectin nanoparticles for diagnostics and treatments; Nuclear Magnetic Resonance (NMR), MRI/ MRM; PET scanning; Visual Molecular Dynamics (VMD)investigations VMD applications in Nanomedicine Prognosis of Alzheimer's Disease (AD) hydrophobic protein nanoparticles hydrophobic lectin nanoparticle structure hydrophobic lectin nanoparticle dynamics lectins clinical trials in cancer 


\section{INTRODUCTION}

Visual Molecular Dynamics (VMD) computer modeling is a readily available, intuitive and powerful tool for studying complex molecular interactions such as protein aggregation and its effect on protein activity and physiological functions. We are reporting the first VMD investigation of the aggregation process of selected proteins, such as hydrophobic lectin nanoparticles, with potentially important applications in Nanomedicine for the prognosis and possibly therapy as well of cancers and Alzheimer's Disease (AD). In the case of AD there is a large body of accumulated evidence that hydrophobic aggregation of modified proteins such as the $\tau-$ (or tau-) and beta-amyloid (or a- $\beta$ ) abeta proteins may actually be the cause of AD. Any attempt at treatment of $\mathrm{AD}$ is however impeded by a lack of understanding of the highly complex interactions involved in the initiation and progression of $\mathrm{AD}$, although- in the very rare cases of $\mathrm{AD}$ with a hereditary component- progress has been made through detailed genetic population models aided by computer statistical analysis. VMD has not been employed so far to unravel the very difficult complexity problems posed by the aggregation of hydrophobic proteins. As discussed in this report, the lectin plant proteins present both a useful model for studying hydrophobic nanoparticle aggregation and a possible approach to improving the prognosis and outcomes of $\mathrm{AD}$ as well as certain types of cancers not yet investigated through clinical trials. Therefore, VMD applications in Nanomedicine have the potential for aiding the design and implementation of successful clinical trials in cancer and AD.

\section{LECTIN APPLICATIONS TO CANCER DETECTION AND TREATMENT}

Lectins are proteins, or more precisely glycoproteins, that agglutinate erythrocytes of some or all blood groups in vitro (Sharon 1998). They are an important group of bioactive proteins and glycoproteins found in most organisms (Baianu and Prisecaru, 2011), including plants, vertebrates, invertebrates, bacteria and viruses, and have several important applications to the fields of health food and medical biotechnology. Lectins are used as tools in the fields of biochemistry, cell biology and immunology, as well as for diagnostic and therapeutic purposes in cancer research (Sharon and Lis 2002). Lectin aggregation can be employed on a large-scale basis for the commercial production of biologically active proteins (Takamatsu et al, 1999). Lectins have been used in glycoprotein purification, oligosaccharide analysis, as well as in cellselection processes. Lectins can bind reversibly with free sugars or with sugar residues of polysaccharides, glycoproteins or glycolipids (Goldstein and Poretz, 1986). There has been 
increasing demand for novel diagnostic and medical cancer therapies that utilize non-traditional sources. Epidemiological studies indicate that the consumption of a plant-based diet is strongly associated with a reduced risk of developing several types of cancer (Block et al, 1992). Plants contain numerous phytochemicals that can alter cancer-associated biochemical pathways. One such group that was investigated examined for its role in cancer chemoprevention is lectins. Lectins were reported to bind preferentially to cancer cell membranes, or their receptors, causing cytotoxicity, apoptosis and/or tumor growth inhibition. Lectins were thought to become internalized into cells, and some lectins were claimed to cause cancer cell agglutination and/or aggregation. Present in common foods, some lectins resist acid and/or enzymatic digestion and also were reported to enter the bloodstream in an intact, and biologically active, form. Lectins possess a spectrum of beneficial, as well as harmful, effects both in vitro and in vivo. Ingestion of lectins also sequesters the available body pool of polyamines, thereby claimed to thwart cancer cell growth. They have also been reported to affect the immune system by altering the production of various interleukins, or by activating certain protein kinases. Lectins were also reported to bind to ribosomes and thus inhibit protein synthesis. Lectins may also modify the cell cycle by inducing non-apoptotic $\boldsymbol{G}_{\boldsymbol{1}}$-phase accumulation mechanisms, $\boldsymbol{G}_{2} / \boldsymbol{M}$ phase cell cycle arrest, and apoptosis, and might activate the caspase cascade. Lectins were also reported to down-regulate telomerase activity and inhibit angiogenesis. Lectins could inhibit cell adhesion, proliferation, colony formation and hemagglutination, and were reported to have cytotoxic effects on human tumor cells. Lectins could function as surface markers for tumor cell recognition, cell adhesion, signal transduction across the membrane, mitogenic cytotoxicity and apoptosis. Also, lectins were reported to modulate the growth, proliferation and apoptosis of premalignant and malignant cells both in vitro and in vivo.

For many years, lectins have been considered to be toxic substances to both cells and animals, mainly because of the observed agglutination of erythrocytes and other cells in vitro. On the other hand, it has also been reported that lectins have an inhibitory effect on the growth of tumors. Their potential for clinical applications has been investigated only in recent years. Lectins are now being considered for use both in the diagnostics and therapeutics of cancers. Thus, lectins are quite versatile biomarkers and have been utilized in a variety of studies involving histochemical, biochemical and functional techniques for cancer cell characterization (Munoz et $a l, 2001)$. Lectins may also be very useful tools for the identification of cancers and the degree of metastasis, or cancer development stage. Recently, there has been a tendency to shift lectins use from cancer detection to actual use in combating cancer. The reason for this shift is mainly 
caused by recent research that indicated the cytotoxic and apoptosis/necrosis-inducing effects of certain lectins, combined with the hypothesis that dietary lectins enter the systemic circulation intact (Wang et al, 1998).

One important feature appears to be that lectins stimulate the human immune system. Lectins were thus reported to exhibit antitumor and anticarcinogenic activities that could be of substantial benefit in cancer treatment. Extracts of Viscum album (mistletoe) are widely used as complementary cancer therapies in Europe. Mistletoe has been used parenterally for more than 80 years as an anticancer agent with strong immuno-modulating action. The quality of life of patients with late-stage pancreatic cancer was reported to be improved on account of exposure to mistletoe lectin (Friess et al, 1996). Immuno-modulation using recombinant ML was reported to influence tumor growth in breast cancer patients (Stein et al, 1998). Bladder carcinoma was reported to be significantly reduced, and survival times were reported to be prolonged in mice as the concentration of ML was increased from 3 to $30 \mathrm{ng}$. ML increased the life span, decreased the tumor growth and decreased hyperplasia of mice and rats with lymphoma and lung cancer (Kuttan et al, 1997).

A lectin purified from mesquite seed was reported to have an anti-proliferative effect on the cervical human tumor (HeLa) cells and on cell adhesion. Vicia faba agglutinin (VFA), a lectin from broad beans was reported to aggregate, stimulate the morphological differentiation of, and reduce the malignant phenotype of colon cancer cells (Jordinson et al, 1999). Wheat germ agglutinin (WGA) proved to be highly toxic to human pancreatic carcinoma cells in vitro. WGA exposure induced chromatin condensation, nuclear fragmentation and DNA release, consistent with apoptosis. The binding of the snail lectin Helix pomatia agglutinin (HPA), which recognizes $\mathrm{N}$-acetylgalactosamine and $\mathrm{N}$-acetylglucosamine sugars, is considered to be a strong predictor of metastasis and unfavorable prognosis in a number of human adenocarcinomas, including breast cancer (Brooks and Carter, 2001). Because of their carbohydrate bio-recognition properties, lectins may also be used as carriers for targeted drug delivery, in a manner similar to liposomes (Wroblewski et al, 2001), provided the possible side effects of such treatments could be minimized.

It has been observed that mucosal expression of terminal unsubstituted galactose is increased in colon pre-cancerous conditions and cancer, and that it allows interaction with mitogenic galactose-binding lectins of dietary or microbial origin. Based on this observation, an interesting 
hypothesis was postulated whereby galactose might be able to prevent cancer by binding and inhibiting such lectins from interacting with colon cancer cells (Evans et al, 2002). D-galactose treatment was reported to be effective in liver lectin blocking to prevent hepatic metastases in colorectal carcinoma patients (Isenberg et al 1997). Epithelial cancer cells showed an increased cell surface expression of mucin antigens with aberrant O-glycosylation, notably ThomsenFriedenreich Antigens (TFA). TFA is a carbohydrate antigen with a proven link to malignancy (Irazoqui et al 2001). Immunoassays could be utilized for antigens such as TFA in order to determine the metastatic potential of breast and colon cancer cells. Molecular changes in the membrane surface in the case of both stomach and colon cancer cells occur during the progression to carcinogenesis. Carbohydrate patterns displayed on the cellular membrane exterior are molecular signatures with unique biological characteristics related to oncogenesis and metastasis, and could be used to determine the appropriate chemotherapeutic and surgical procedures for each specific cancer.

Lectins have already a demonstrated potential for the treatment, prevention and diagnosis of chronic diseases such as cancer. However, further research is required to elucidate the effects of purified and dietary lectins and their potential for defense against tumors.

\section{COMPUTATIONAL BIOLOGY, MOLECULAR MODELING AND THEIR BIOMEDICAL APPLICATIONS IN NANOMEDICINE}

Computational Biology has a very wide range of applications currently thought of 'belonging' to Biotechnology (Baianu, 1986) and Bioinformatics (Baianu, 2011), even though the development of such computations has preceded modern Biotechnology by many decades. Our approach is to focus on a few selected examples in greater depth, by considering molecular modeling techniques that have very wide applications, ranging from 'pure' chemistry to Biochemistry, Molecular Biology, Biotechnology, Nanomedicine, Pharmacology and Pharmacogenomics.

\subsection{Molecular Modeling Techniques}

Molecular modeling is a group of techniques that employ computer-generated images of chemical structures that show the relative positioning of all the atoms present in the molecule being studied, and/or the simulated dynamics of such molecules together with their ordering through space-time. Such techniques are of considerable help for understanding many 
physicochemical properties of molecules, and may also provide clues about their possible role(s), that is, their function, in the organism. They can be thus especially valuable tools for investigating structure-function relationships. Proteins --within a given protein family-- have, in theory, similar sequences and generally share the same basic structure. Thus, once the structure for one member of the protein family is determined, molecular modeling computations can help determine the structure for other members of the same protein family. Such a homology technique when applied to protein structure may allow scientists to gain additional insight into protein structure, especially for those proteins for which the available experimental data is scarce.

\title{
3.1.1 Tasks in Molecular Modeling
}

In order to obtain optimal results, the National Center by Biotechnology (NCBI) suggested that protein sequences should be organized in protein families. Such readily searchable databases (Table 4) are currently available for many proteins (NCBI -2003).

\section{Table 4. Databases for Molecular modeling}

\author{
Protein Data Bank (PDB); \\ The molecular modeling database (MMDB) at NCBI \\ Clusters of Orthologous Group of proteins (COGs) with the COGNITOR program \\ The Basic Local Alignment Search Tool (BLAST) \\ Vector Alignment Search Tools (VAST) \\ The Conserved Domain Database(CDD) \\ Domain Architecture Retrieval Tool (DART).
}

(Source: NCBI 2003: “A Science primer” ).

Secondly, a target must be selected. A target is a protein structure that has been determined via experiments. Thirdly, one must generate a purified protein for analysis of the chosen target and then determine the protein structure by analytical techniques such as X-ray crystallography and/or 2D-FT NMR.

The experiments described next, for example, studied apolipoprotein $A-1$ by employing molecular modeling techniques in order to understand the interaction of proteins in food systems and complex organisms. 


\subsubsection{Apolipoprotein Structures}

Lipoprotein in mammals have evolved as the primary transport vehicles for lipids. This role leads to the importance of lipoproteins in several diseases, such as atherosclerosis and cardiovascular disease. Lipoprotein particles consist of a core of neutral lipids, stabilized by a surface monolayer of polar lipids complexed with one or more proteins.

Apolipoprotein A-I and apo B are respectively, the major protein components of high-density (HDL) and very low density (VLDL) lipoproteins. Thus, understanding apolipoproteins is very important for medical and health-related fields, such as medical biotechnology, as well as food science and human nutrition.

\subsubsection{Methods of Structure Determination applied to Apolipoprotein Molecules}

The process of biosynthesis, the physical characteristics and the metabolism of apolipoproteins have been intensely studied. However, because of the non-crystalline, or paracrystalline structure of many apolipoproteins (Baianu, 2012), it has been difficult to obtain structural data at the molecular, or atomic level. Therefore, methods combining the amino acid sequence with molecular methods are now being introduced. Thus, overall structures may be derived from correlations of global secondary structures determined from polarized light studies combined with local structures predicted from amino acid sequences. The known amino acid sequence of apolipoprotein from the position 7 to 156 of apo Lp-III was first used to design an Apo A-I template, that could be then approached by 'standard' molecular modeling techniques.

\subsubsection{Molecular Modeling of Apolipoproteins A-I}

Target: Apolipoprophorin III is chosen as a target for apolipoprotein A-I.(apo Lp A-I) . The structure of Apolipophorin III has been determined in a crystal at $2.5 \AA$ resolution for the 18 $\mathrm{kDa}$ apo Lp III from the African migratory locust, Locusta migratoria and the 22-kDa Nterminal, receptor-binding domain of human apo E.

Template for Apo A-I: Lp IIIa is designed by using molecular software IALIGN from Lp III by inserting alanine for template of sequences of apo A-I ( using the program SYBYL, v.5.5). Alanine residues are inserted at each of the gap position identified by IALIGN, an interactive 
alignment program distributed with the Protein Identification Resource (PIR; Eleanor M.B, 1994) This model was compared with DgA-I, HuA-I and ChA-I resprsenting canine, human and chicken Apo A-I respectively. Results were then compared using a "strip of the helix" template (Vazquez et al 1992) by scoring 1 or 0 for residues that did, or did not, fit into the template.

\section{Modeling Results.}

A. Sequence Comparison. The five long $\alpha$-helices connected by short loops in amino acid residues 7-156 of apo Lp-III is used as template for LpIIIa, Dig A-I, DgA-I, HuA-I. Amphipathic potential (AP) is used to detect if the predict structure is suitable for a lipid-aqueous interface in its stable condition. The results are shown in Table $\mathbf{5}$.

Table 5: Amphipathic potentials** of predicted helical segments in apolipoprotein models.

\begin{tabular}{|c|c|c|c|c|c|c|c|c|c|c|}
\hline \multicolumn{11}{|l|}{ Model } \\
\hline & \# res & $\overline{\mathbf{A P}}$ & \# res & $\overline{\mathbf{A P}}$ & \# res & $\overline{\mathbf{A P}}$ & \# res & $\overline{\mathbf{A P}}$ & \# res & $\mathbf{A P}$ \\
\hline Lp-III & 19 & 0.79 & 25 & 0.8 & 22 & 0.77 & 27 & 0.7 & 21 & 0.67 \\
\hline Lp-IIIa & 19 & 0.79 & 25 & 0.8 & 24 & 0.67 & 33 & 0.61 & 22 & 0.64 \\
\hline DgA-I & 19 & 0.58 & 25 & 0.84 & 24 & 0.75 & 33 & 0.48 & 22 & 0.68 \\
\hline HuA-I & 19 & 0.53 & 25 & 0.88 & 24 & 0.71 & 33 & 0.45 & 22 & 0.73 \\
\hline ChA-I & 19 & 0.53 & 25 & 0.88 & 24 & 0.58 & 33 & 0.52 & 22 & 0.82 \\
\hline
\end{tabular}

**Amphipathic potentials (AP) are the best average value for a helical segment of ( \# res) residues measured with the "strip of helix".(Vazquez, et al. 1992)

B. Energy minimized models. In this model, electrostatic interactions contributes the most to favorable energies. Alanine was chosen as the spacer residue in building apo Lp-IIIa because of its function of small, non-ionic side chain and serves as a helix-stabilizing residue. Although it has a high probability of being found in helical structures, it does not participate through electrostatic interactions. Results of this model are discussed for potential energetic evaluation and amphipathic analysis of energy refined helices (see Table 6 and Table 7). The structure obtained through this molecular modeling is illustrated in Figure 6. 


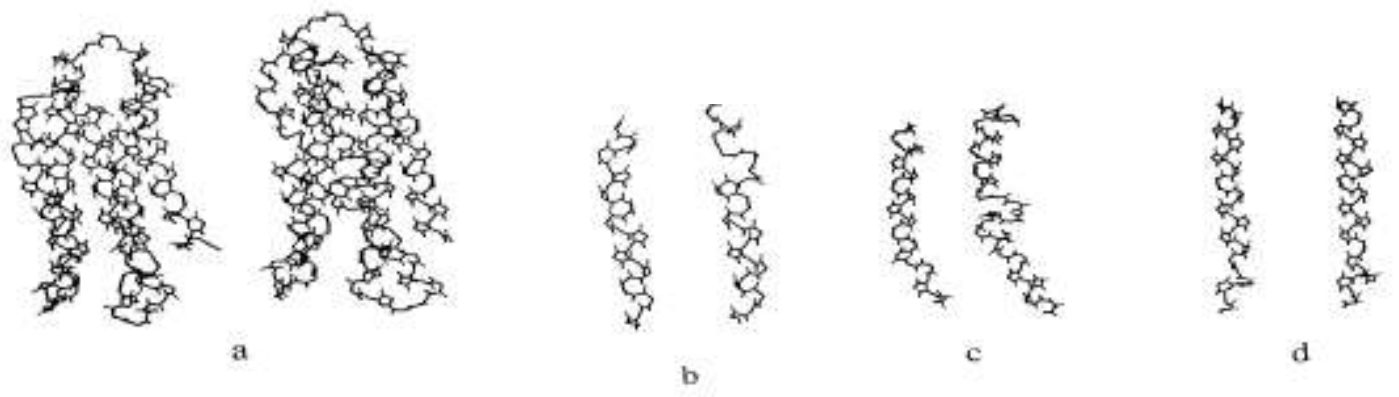

Figure 6. Energy Refined models of apo-Lp III and the template apo IIIa constructed by inserting alanine residues into gap positions identified when the sequences were aligned with the canine, human, and chicken apo A-1 sequences. Backbone structures for this complete models are in panel (a). The effects of inserted alanine residues on $\mathrm{H} 3, \mathrm{H} 4, \mathrm{H} 5$ are displayed in panels (b), (c), (d) respectively. In each display, the apo Lp III is shown to the left of the apo Lp-IIIa. (SOURCE: Brown et al, 1994).

Table 6. Energetic evaluation of the refined models

\begin{tabular}{|c|c|c|c|c|c|}
\hline & Lp-in & Lp-IUa & DgbjA-I & HuA-I & ChA-I \\
\hline Number of residues & 150 & 165 & 165 & 165 & 165 \\
\hline \multicolumn{6}{|l|}{ Energy, kcal } \\
\hline Bond stretching & 20.7 & 23.1 & 28.9 & 29.2 & 31.8 \\
\hline angle bending & 123.4 & 154.0 & 189.6 & 208.5 & 212.2 \\
\hline torsional & 198.1 & 235.7 & 308.3 & 324.6 & 340.9 \\
\hline out of plane & 26.1 & 35.8 & 37.7 & 41.5 & 44.5 \\
\hline 1-4 van der Waals & 218.7 & 235.6 & 247.2 & 260.2 & 270.3 \\
\hline van der Waals & -993.0 & -1094.3 & -1074.8 & -1131.8 & -1155.6 \\
\hline 1-4 electrostatics & 1684.0 & 1813.3 & 1497.1 & 1566.7 & 1524.1 \\
\hline electrostatic & -4497.8 & -4567.3 & -5214.7 & -5182.6 & -5208.4 \\
\hline H-bond & -69.3 & -70.2 & -64.5 & -69.8 & -76.3 \\
\hline Total Energy, kcal & -3289.0 & -3234.3 & -4045.2 & -3953.6 & -4016.4 \\
\hline $\mathrm{kcal} / \mathrm{mol} / \mathrm{residue}$ & -21.9 & -19.6 & -24.5 & -24.0 & -24.3 \\
\hline H1 (residues) & $(7-25)$ & & $(72-90)$ & $(73-88)$ & $(72-90)$ \\
\hline $\mathrm{kcal} / \mathrm{mol} / \mathrm{residue}$ & -16.1 & & -18.5 & -16.6 & -17.4 \\
\hline H2 (residues) & $(35-59)$ & & $(100-124)$ & $(101-125)$ & $(100-124)$ \\
\hline $\mathrm{kcal} / \mathrm{mol} / \mathrm{residue}$ & -16.1 & & -20.1 & -19.4 & -19.2 \\
\hline H3 (residues) & $(70-91)$ & $(70-91)$ & $(135-158)$ & (136-159) & $(135-158)$ \\
\hline $\mathrm{kcal} / \mathrm{mol} / \mathrm{residue}$ & -17.6 & -20.7 & -18.4 & -16.2 & -17.6 \\
\hline H4 (residues) & $(96-121)$ & $(96-121)$ & $(166-196)$ & $(167-197)$ & $(166-196)$ \\
\hline $\mathrm{kcal} / \mathrm{mol} / \mathrm{residue}$ & -15.5 & -13.8 & -16.7 & -16.9 & -17.6 \\
\hline H5 (residues) & $(136-155)$ & $(136-155)$ & $(207-235)$ & $(208-236)$ & $(207-235)$ \\
\hline $\mathrm{kcal} / \mathrm{mol} / \mathrm{residue}$ & -15.8 & -15.4 & -14.0 & -13.4 & -14.9 \\
\hline
\end{tabular}


These energy calculations, based on the sequence segments initially assigned to HI -H5 (see Tables 6 and 7), are given to illustrate the stability of the structures. Sequences for helices 3 to 5 (H3, H4, H5) of apo Lp-IIIa contain inserted alanine residues. (Source: Brown, 1994).

Table 7. Amphipathic analysis of energy refined helices

\begin{tabular}{|c|c|c|c|c|c|}
\hline Model & Lp-III & Lp-IIIa & gA-I & HuA-I & ChA-I \\
\hline $\mathrm{HI}$ & N7-E25 & N7-E25 & D72-E90 & D73-K88 & E72-E90 \\
\hline Hb sector & $140^{\circ}$ & $140^{\circ}$ & $100^{\circ}$ & $60^{\circ}$ & $100^{\circ}$ \\
\hline Av. $\mathrm{Hb}$ & 0.98 & 0.98 & 0.78 & 0.7 & 0.81 \\
\hline $\mathrm{H} 2$ & P35-S59 & P35-S59 & L100-E124 & L101-E125 & L101-E124 \\
\hline $\mathrm{Hb}$ sector & $100^{\circ}$ & $100^{\circ}$ & $100^{\circ}$ & $100^{\circ}$ & $100^{\circ}$ \\
\hline Av. $\mathrm{Hb}$ & 0.8 & 0.8 & 0.7 & 0.89 & 0.95 \\
\hline $\mathrm{H} 3$ & S70-T91 & S70-S85 & Q137-R150 & E136-R149 & L135-L151 \\
\hline $\mathrm{Hb}$ sector & $140^{\circ}$ & $120^{\circ}$ & $100^{\circ}$ & $100^{\circ}$ & $120^{\circ}$ \\
\hline Av. Hb & 0.93 & 0.79 & 0.95 & 0.88 & 0.82 \\
\hline \multicolumn{6}{|l|}{$\mathrm{H} 4$} \\
\hline $\mathrm{H} 4 \mathrm{~A}$ & A96-S121 & Q98-T107 & D168-K181 & Q172-E179 & D167-R181 \\
\hline $\mathrm{Hb}$ sector & $100^{\circ}$ & $140^{\circ}$ & $80^{\circ}$ & $100^{\circ}$ & $80^{\circ}$ \\
\hline Av. $\mathrm{Hb}$ & 0.56 & 0.91 & 1.1 & 0.94 & 1.18 \\
\hline $\mathrm{H} 4 \mathrm{~B}$ & & Q117-al21d & S187-S196 & A190-A194 & P186-V195 \\
\hline Hb sector & & $60^{\circ}$ & $100^{\circ}$ & & $60^{\circ}$ \\
\hline Av. Hb & & 0.45 & 0.45 & & 0.66 \\
\hline H5 & E136-V156 & L134-A155 & L213-I232 & L214-T237 & E212-L235 \\
\hline Hb sector & $120^{\circ}$ & $80^{\circ}$ & $100^{\circ}$ & $100^{\circ}$ & $100^{\circ}$ \\
\hline Av. $\mathrm{Hb}$ & 0.74 & 0.53 & 1.05 & 0.96 & 0.86 \\
\hline
\end{tabular}

Table 7. The size of the hydrophobic $(\mathrm{Hb})$ sector of a helix was determined from helical Wheel projections (Schiffer et al 1967) The average hydrophobicity (Av. Hb), of this sector was calculated by the method of Eisenberg (1984). Single letter designations are used for Amino acid residues, (al21d) designates the fourth alanine residue inserted between residues 121 and 122 of Lp-III. (Source: Brown, 1994).

After evaluating the potential energy for this model, the lateral view structures of apolipoproteins for apo lipophorin III(residues 7-156), canine apolipoptrotein A-I (residues 72-236), human apolipoprotein A-I (residues 73-237) and chicken apolipoprotein A-I (residues 72-236). The computation results are shown in Figure 7 (according to Brown, 1994). 


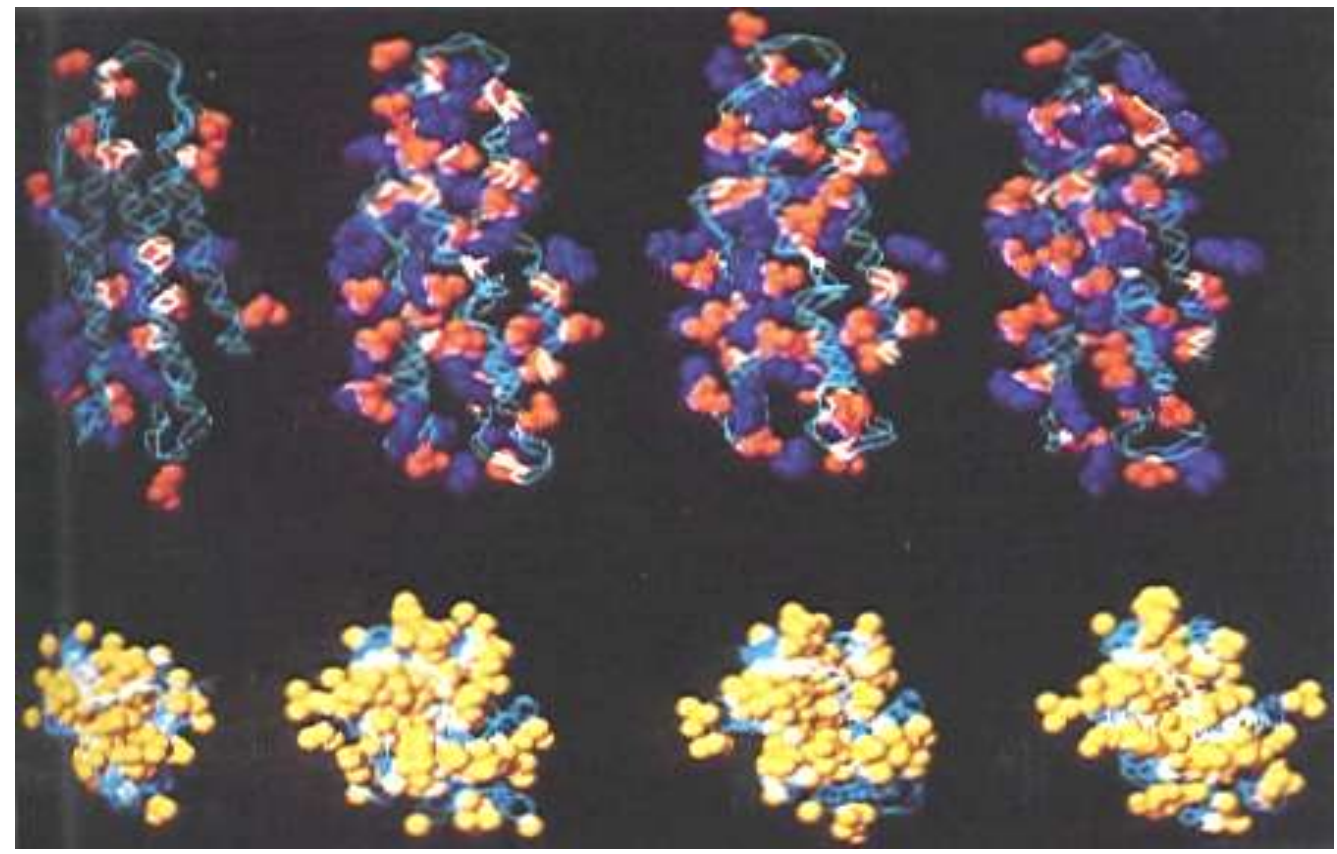

Figure 7. Energy refined models of from left to right apo lipophorin III(residues 7-156) canine apolipoptrotein A-I (residues 72-236), human apolipoprotein A-I (residues 73-237) and chicken apolipoprotein A-I (residues 72-236). Peptide backbones are represented by a double stranded ribbon. In the lateral view, only ionizable sidechains are displayed with acidic groups in red and basic groups in blue. In the end-on view of the molecules only the hydrophobic sidechains are displayed in orange. (Source: Brown, 1994)

\subsection{Combination of Molecular Modeling with Other Techniques}

It is important to combine molecular modeling with other techniques in order to improve the accuracy of the modeling results. A recent study of Apolipoprotein has produced a highresolution reconstruction of the structure of apolipoprotein through combination with a solutionphase X-ray technique. It was shown that Apoliproprotein A-1 is an 243-residue protein that contains a globular amino-terminal domain (residue 1-43) and a lipid-binding carboxyl-terminal domain (residues 44-243; Segrest et al, 1992). The aqueous phase X-ray diffraction crystal structure was obtained at $4 \AA(0.4 \mathrm{~nm})$ resolution, which is moderate. This has suggested the accuracy of molecular modeling by combining the X-ray crystallographic with molecular modeling (Figure 8; from Segrest et al, 1992.; Borhani, 1997). 


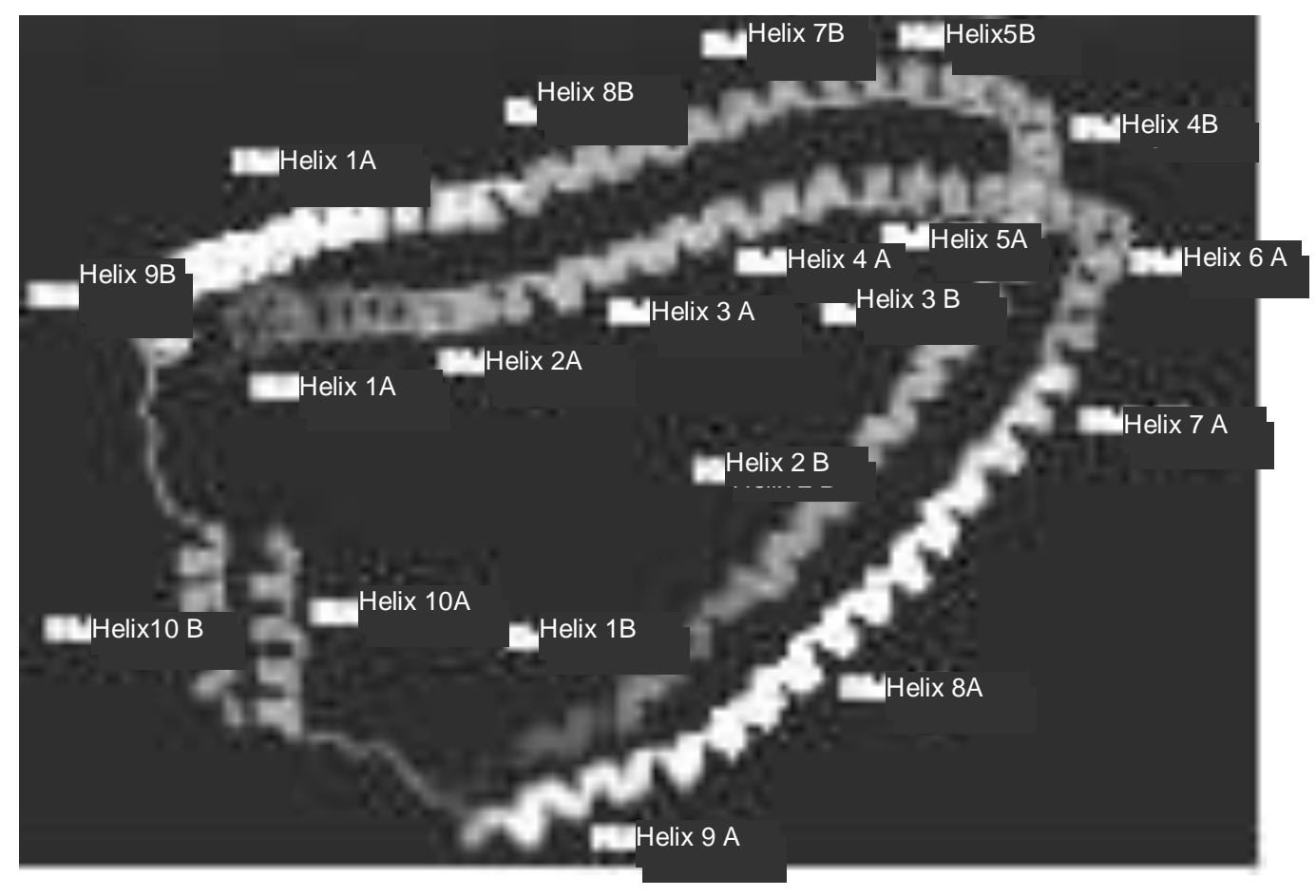

Figure 8. X-ray Diffraction Crystal structure of the Apolipoprotein A-I: $\Delta($ 1-43) dimer in solution. (Source: Borhani et al. 1997).

\subsection{In-Depth Analyses of Molecular Structure}

The determination of apolipoprotein A-I can be then further associated with lipid containing domains by employing other molecular modeling techniques, such as VMD (generated in The Beckman Research Institute at the University of Illinois at Urbana, IL, USA) . The 'belt model' is used to show the possible orientations of lipoprotein with its apolipoprotein inserted (Figure 9). The suggested structure can then serve as a template in other high density lipoproteins for their structure determination and also help in understanding the biological interaction. 


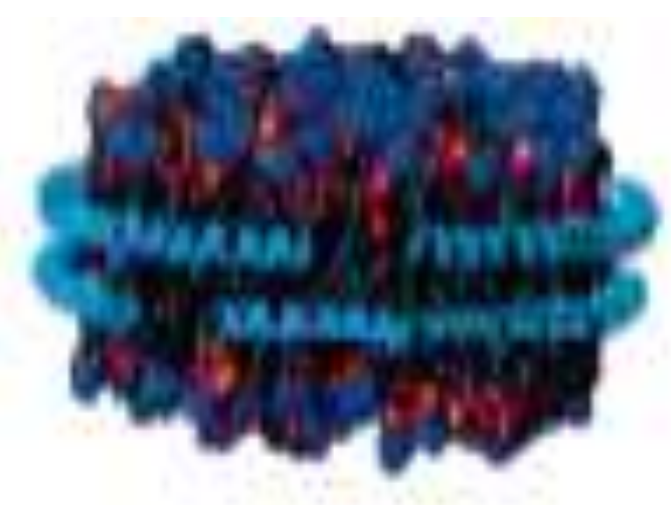

Fig 9a. Detailed Belt model displayed as a helical ribbon. $\mathrm{C}\left(\mathrm{NH}_{2}\right)_{3}$, blue, oxygen atom, red; phosphorous atom, yellow all other atom, black.

( Source: Borhani 1997)

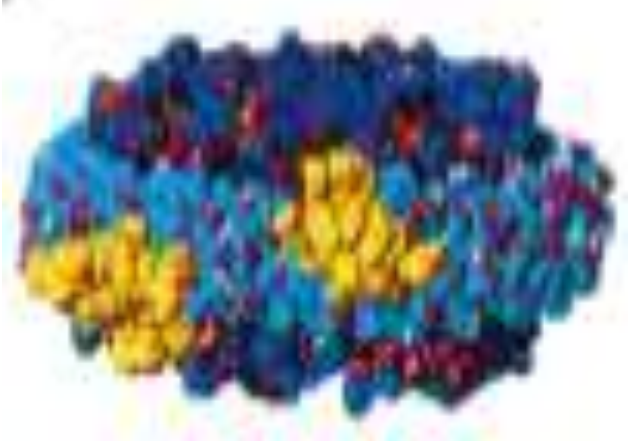

Fig 9b. Detailed Belt model displayed as all atom model, oriented in 9a. nitrogen atom, blue, oxygen atom, red; carbon atom, cyan, polar hydrogen atom, white. ( Source: Borhani 1997)

\subsection{Practical Applications of Molecular Modeling}

Molecular modeling has been introduced for more than two decades ago. Increasingly, modeling software is available for a variety of industrial applications. Global markets for molecular modeling, in general, currently exceed 2 billion US \$ annually (Fuji-Keizai, 2003).

\subsubsection{Examples of Medical Applications of Molecular Modeling}

Molecular modeling is especially helpful in the medical/biomedical and pharmacological fields, such as in nanoscale development of novel drugs of increased potency. Recent studies have shown the importance of using molecular modeling in medical, food sciences and nutrition (Food Ingredient first, 2003). The molecular modeling of Epigallocatechin Gallate (EGCG), and the HIV cell was undertaken by Shearer (2003). His report has inspired scientists in Japan who discovered the potential of green tea as an anti-HIV drug. The chemical compound that is found abundantly in the green tea called Epigallocatechin Gallate (EGCG) is reported to stop the HIV virus from binding to CD4 molecules and human T-cells.

\subsubsection{Other Applications of Molecular Modeling}

Other applications of molecular modeling to pharmacology, manufacturing, life sciences and chemistry greatly benefit from such molecular modeling programs. Nanotechnology has developed to a 30 to 40 million US \$ market, and it also has the potential to grow to a 60 to 70 million US \$ market within the next five years (Fuji-Keizai, 2003). 


\section{CONCLUSIONS}

A summary and simplified overview of the selected applications of nanotechnology in the areas of Nanomedicine, foods, human nutrition and health- as well as the potential large-scale applications in the chemical industry- that were discussed in this report is presented in Table 8.

Table 8. Selected Biotechnology and Nanotechnology Tools and Their Applications

\begin{tabular}{|c|c|l|}
\hline NOVEL TECHNIQUES & \multicolumn{1}{|c|}{ AREA } & \multicolumn{1}{|c|}{ APPLICATION } \\
\hline \multirow{4}{*}{ Immobilized cells } & Food Applications & $\begin{array}{l}\text { Brewing industry } \\
\text { Dairy Foods }\end{array}$ \\
\cline { 2 - 2 } & Human Nutition & Neutraceuticals \\
\cline { 2 - 3 } & Medical Applications & $\begin{array}{l}\text { Regulation of fibrinolisis } \\
\text { Detoxification of water }\end{array}$ \\
\hline
\end{tabular}

\begin{tabular}{|c|c|c|}
\hline \multirow{4}{*}{ Genetic Manipulation } & Food Applications & \multirow{4}{*}{$\begin{array}{l}\text { Synthesis of complex carbohydrates } \\
\text { cloning of cellulose degrading enzyme } \\
\text { Addition of vitamins in foods } \\
\text { Reduction of ripening }\end{array}$} \\
\hline & Human Nutrition & \\
\hline & Medical applications & \\
\hline & Other & \\
\hline \multirow{3}{*}{ Liposomes in Microencapsulation } & Food Applications & \multirow{3}{*}{$\begin{array}{l}\text { Flavor delivery } \\
\text { Additives in bakery } \\
\text { Chesee ripening } \\
\text { protecion of DNA interactions } \\
\text { Gene therapy } \\
\text { Vaccines } \\
\text { Drug carrier against Cancer and HIV } \\
\text { Creams } \\
\text { Oil spills separations }\end{array}$} \\
\hline & Medical applications & \\
\hline & Other & \\
\hline
\end{tabular}

The rapid development of biotechnological tools and 'quick' applications oriented towards immediate marketing may be responsible for generating legislative barriers against 'GMO-based' products. The complementary area of genetically manipulated microorganisms is adopting novel approaches to overcome such increasingly unprofitable legislative barriers and boost profits both in the short- and long-term.

The use of ultra-sensitive techniques and biocomputational modeling is essential in order to quantitate the physical and chemical properties of molecules and supra-molecular systems that are of primary interest to developments in nanotechnology and its applications to Nanomedicine. 
Policy changes may be therefore considered and implemented that would take advantage of such novel approaches to develop new niches and markets for both profitable and safe Nanotechnology applications worldwide, in the Chemical Industry, Agriculture, Health and Medicine.

\section{REFERENCES}

1. Alkhalaf W., Piard J.C., Soda M.C., Gripon J.C., Desmezeaud, M. and Vassa, IL. 1988. Liposomes as proteinase carriers for the accelerated ripening of St. Paulin type cheese. Journal of Food Science. 53: 1674-1679.

2. Anderson R.A, Paquette S, Lovrien R. 2002. Lectin-erythrocyte interaction with external transmembrane glycohphorin saccharides controlling membrane internal cytoskeleta. J. Agric. Food Chem. 50 (22): 6599-604.

3. Andrews AL, Atkinson D, Barratt MD, Finer EG, Hauser H, Henry R, Leslie RB, Owens NL, Phillips MC and Robertson RN. 1976. Eur. J. Biochem. 64, 549-563.

4. Andries M, van Beveren PC, Goffin O, and Masschelein CA.1996. European Brewing. Convention. p.134-144

5. Babu PS and Panda T.1991. Studies on improvement techniques for immobilizing and stabilizing penicillin amidase associated with E. coli cells. Enzyme Microbial Technology. 13: 676-682.

6. Baianu I.C. 2012. Paracrystalline Nano-Structure and Dynamics. In: Nanoscience and Nanotechnology. E. Lyshevsky, Editor; CRC Press-Taylor and Francis. 24 pages (in press).

7. Baianu I.C and V. Prisecaru. 2011. NMR, NIR, and Infrared Spectroscopy of Protein-Carbohydrate Interactions and Glycoproteins. ACS Symposium Series, 1077: 337-352.

8. Baianu, I.C. 2011. Translational Oncogenomics and Human Cancer Interactomics: Advanced Techniques and Complex System Dynamic Approaches. Bioinformatics Trends and Methodologies, 2: 473-510.

9. Baianu, I.C. 2011. The First Report of 1 Micron Spatial Resolution Chemical Imaging of a Zirconium Single Crystal by FT-NIR Microspectroscopy, Chemo.philica, Article number 272: 1-5.

10. Baianu I.C. 1986. Computer models and automata theory in biology and medicine. Mathematical Modelling. 7: 1513-1577.

11. Baianu IC, Magin R and Ozu E. 1993. Microencapsulation adds value to Illinois crops. Illinois Research. 35(1):19-21. 
12. Baianu IC, Kumosinski TF, Bechtel PJ, Myers-Betts PA, Kakalis LT, Mora-Guttierrez A, Yakubu P and Wei TC. 1988. NMR Studies of Chemical Activity and Protein Interactions in Solutions and Hydrated Powders. In: Proceed.196th National Meeting of the American Chemical SocietyDivision of Agriculture and Food Chemistry. American Chemical Society p.156.

13. Baianu IC, Ozu EM, Wei TC and Kumosinski TF. 1993. Molecular Dynamics and NMR Studies of Concentrated Electrolytes and Dipoles in Water. In: Molecular Modeling. ACS Symp. Ser. 576. Kumosinski TF and Liebman M, eds. ACS: Washington, D.C. p. 269-324.

14. Baianu IC, Ozu EM, Wei TC and Kumosinski TF. 1993. In: Molecular Modeling. ACS Symp. Ser. 576. Kumosinski TF and Liebman M, eds. ACS: Washington, D.C. p. 325-341.

15. Baianu, I.C., H. Pessen and T.F. Kumosinski. 1995. Physical Chemistry of Food Processes . Vol.2., New York: Van Nostrand-Reinhold., pp.602.

16. Banka CL, Bonnet DJ, Black AS, Smith RS, Curtiss LK.1991. J. Biol. Chem. 266:2388623892.

17. Blaschek HP and White B. 1993 Renewed interest in renewable fuels. Illinois Research. 35(1): 12-13.

18. Blaschek HP. 1996. Recent Develpoments in the Genetic Manipulation of Microorganims for biotechnology applications. In: Baianu IC, Pessen H and Kumosinski TF, eds. Physical Chemistry of Food Processes. Vol 2. New York: Van Nostrand Reinhold. p. 459-474.

19. Block G, Patterson B, Subar A.1992. Fruit, vegetables, and cancer prevention: a review of the epidemiological evidence. Nutr. Cancer. 18(1): 1-29.

20. Blundell TL and Johnson LN. 1976. Protein Crystallography. Academic Press: New York, NY.

21. Blue M-L, Ostapchuk P, Gordon JS, Williams DL. 1982. J. Biol. Chem. 257: 11151-11159

22. Boguski MS, Freeman M, Elshourbagy NA, Taylor JM, Gordon JI. J. Lipid Res. 1986, 27, 1011-1034.

23. Borhani DW et al. 1997. Crystal Structure of truncated human apolipoprotein A-I suggests a lipid-bound conformation. Proc Natl. Acad. Sci. USA. 94: 12291-12296

24. Brooks SA and Carter TM. 2001. N-acetylglucosamine and sialic acid expression in primary breast cancers. Acta. Histochem. 103(1): 37-51.

25. Brown EM.1989. Poultry Science. 68: 399-407.

26. Brasseur R. J. Biol. Chem. 1991, 266, 16120-16127.

27. Brasseur R, Lins L, Vanloo B, Ruysschaert J-M, Rosseneu M.1992. Proteins. 13: 246-257. 
28. Breiter DR, Kanost MR, Benning MM, Wesenberg G, Law JH, Wells MA, Rayment I and Holden HM. 1991. Biochemistry. 30: 603-608.

29. Cary JW, Petersen DJ, Papoutsakis ET, and Bennett GN.1988. Cloning expression of Clostridium acetobutylicum phosphotrans-butyrylase and butyrate kinase genes in Escherichia coli. J. Bacteriol. 170:4613-4618.

30. Chapman MJ.1986. Meth. Enzymol. 128: 70-143.

31. Chassy BM, and Flinkinger JL.1987. Transformation of Lactobacillus casei by electroporation. FEMS Microbiol. Lett. 44: 173-177.

32. Chibata I. 1979. Immobilized microbial cells with polyacrylamide gel and carrageenan and their industrial applications. In Immobilized Microbial Cells, ACS Symposium Series 106. Venkatsubramanian K ed. Washington DC: American Chemical Society. p. 187-202.

33. Chou PY and Fasman GD. 1978. Adv. Enzymol. 47: 45-148.

34. Cole KD, Fernando-Warnaku1asuriya GJP, Boguski M, Freeman M, Gordon JI, Clark WA, Law JH, Wells MA. 1987. J. Biol. Chem., 262: 11794-11800.

35. Deamer DW and Uster PS. 1983. Preparation of Liposomes. In: Ostro M.J. ed. Liposomes. Marcel Dekker. p. 1.

36. De Loof H. 1988. Ann. Biol. Clin.46, 10-15.

37. Dutton G. 1993. The promise of liposomes. Gen. Engin. News. 13: 6-9.

38. Eisenberg, D. 1984. Annu. Rev. Biochem. 53: 595-623.

39. El-Aassar SA, el-Badry HM, Abdel-Fattah. 1990. The biosynthesis of proteases with fibrinolytic activity in immobilized cultures of Penicillium chrysogenum H9. Microbiol Biotechnol. 33(1): 26-30.

40. Eleanor MB.1994. Molecular modeling of Apoliprotein A-I. Using Template derived from crystal structure of Apolipophorin III. In: Molecular Modeling. ACS Symp. Ser. 576.

Kumosinski TF and Liebman M, eds. ACS: Washington, D.C. p. 100-112.

41. Evans RC, Fear S, Ashby D, Hackett A, Williams E, Van Der Vliet M, Dunstan FD and Rhodes JM.2002. Diet and colorectal cancer: An investigation of the lectin/galactose hypothesis, Gastroenterology, 122 (7): 1784-1792.

42. Friess H, Beger HG, Kunz J, Funk N, Schilling M, Buchler MW.1996. Treatment of advanced pancreatic cancer with mistletoe: results of a pilot trial. Anticancer Res, 16(2): 915920.

43. Garnier J, Osguthorpe DJ, Robson B. 1978. J. Mol. Biol. 120: 97-120. 
44. Goldstein IJ, and Poretz, RD.1986. Isolation, physicochemical characterization, and carbohydrate-binding specificity of lectins. In: Liener, IE, Saron N, and Goldstein IJ, ed. The Lectins: Properties, Functions, and Applications in Biology and Medicine. London: Academic, p. 33-237.

45. Gatt S, Bercovier JH and Barenholz Y.1991. Use of liposomes to combat oil spills and their potential application to bioreclamation. In: Hinchee RE and Olfenbutte RF, eds. On Site Bioreclamation. Butterworth, Stoneham p. 293-312.

46. Glomset JA. 1968. Lipid Res. 9: 155-167.

47. Gregoriadis G, ed.1984. Liposome Technology. New York: CRC Press.

48. Gregoriadis G and Allison AC. 1990. Liposomes in Biological Systems. New York: John Wiley \& Sons.

49. Haran N and Shporer M. 1976. Biochem. Biophys. Acta 426: 638-646.

50. Head IM, Bailey MJ. 2003. Environmental biotechnology. Methodological advances spawn new concepts in environmental biotechnology. Current Opinion in Biotech 14 (3): 245-247.

51. Hofe EH, Billings PC, Heidelberger C. and Landolph JR. 1986. In vitro genotoxicity studies using complex hydrocarbon mixtures. Environ. Mutagen. 8: 589-609.

52. Inoue T. 1995. European brewing: proceedings of the twenty fifth convention. p.25-36.

53. Irazoqui FJ, Jansson B, Lopez PH, and Nores GA. 2001. Correlative fine specificity of several Thomsen-Friedenreich disaccharide-binding proteins with an effect on tumor cell proliferation. J. Biochem. (Tokyo).130(1): 33-7.

54. Isenberg J, Stoffel B, Stutzer H, Otte K, and Beuth J.1997. Liver lectin blocking with Dgalactose to prevent hepatic metastases in colorectal carcinoma patients. Anticancer Res. 17(5B): 3767-72.

55. Jordinson M, El-Hariry I, Calnan D, Calam J, and Pignatelli M.1999. Vicia faba agglutinin, the lectin present in broad beans, stimulates differentiation of undifferentiated colon cancer cells. Gut. 44:709-714.

56. Karel SF, Libicki SB and Robertson CR. 1985. Immobilization of whole cells Chemical Engineering Science, 40:1321-1354.

57. Kim H and Baianu IC. 1991. Novel liposomes microencapsulation techniques for food applications. Food Science and Technology. 2(3): 49-77

58. Kirby CJ and Law B. 1987. In: Andrews, AT, ed. Chemical Aspects of Food Enzymes. Royal Society of Chemistry. p. 106-119.

59. Kolot FB. 1981. Microbial carriers: Strategy for selection. Proc. Biochemistry, 16: 30-46. 
60. Kyte J, Doolittle RF. 1982. J. Mol. Biol.157: 105-132.

61. Kollman P. 1987. Ann. Rev. Phys. Chem. 38: 303-316.

62. Kumosinski TF, Brown EM, Farrell HM Jr. 1991. J. Dairy Sci. 74: 2879-2888.

63. Kuttan G. 1997. Anticarcinogenic and antimetastatic activity of Iscador. Anti-Cancer Drugs. $8: 15-16$.

64. Lasic DD. 1993. Liposomes: From Physics to Applications. Amsterdam: Elsevier.

65. Li WH, Tanimura M, Luo CC, Datta S and Chan L.1988. J. Lipid Res. 29: 245-271.

66. Linko P.1985. Fuel and industrial chemical through biotechnology. Biotechnology Advances. 3(1): 39-63.

67. Lou C-C, Li WH, Moore MN, Chan L. 1986. J. Mol. Biol. 187:325-340.

68. Lux SE, Hirz R, Shrager RI. and Gotto AM.1972. J. Biol. Chem., 247: 2598-2606.

69. McLachlan AD. 1977. Nature, 267: 465-466.

70. Maddox IS.1980. Production of n-butanol from whey filtrate using Clostridium acetabutylicum NCIB 2951. Biotechnol. Lett. 2: 493-498.

71. Maddox, IS and Murray AE.1983. Production of n-butanol by fermentation of wood hydrolysate. Biotech. Lett. 5:175-178.

72. Mahley RW, Innerarity TL; Rall SC. Jr.; Weisgraber, KW. 1984. J. Lipid Res. 25: 12771294.

73. Marcel YL, Provost PR, Koa H, Raffai E, Dac NV, Fruchart J-C, Rassart E. 1991. J. Biol. Chem. 266: 3644-3653.

74. Masschellein CA, Ryder DS and Simon JP. 1994. Critical Reviews in Biotechnology 14 (2): 155- 177 .

75. Mayhew E and Lazo AM. 1984. Biochem. Biophys. Acta. 775: 169-174.

76. Mayhew E and Papahadjopoulos D. 1983. In: Ostro MJ, ed. Liposomes. Marcel Dekker. p. 289.

77. Munoz R, Arias Y, Ferreras JM, Jimenez P, Rojo MA, and Girbes T. 2001. Sensitivity of cancer cell lines to the novel non-toxic type 2 ribosome-inactivating protein nigrin $b$. Cancer Lett. 167(2): 163-169.

78. National Biomedical Research Foundation, Georgetown University Medical Center.1991.Washington DC. Release 28.0. March 31

79. Nedovic V, Leskosek-Cukalovic I and Vunjak-Novakovic G. 1999. Immobilized cell technology (ict) in beer fermentation - a possibility for environmentally sustainable and costeffective process. University of Belgrade. www.rcub.bg.ac.yu.

80. Nedovic VA, Leskosek-Cukalovic I and Vunjak-Novakovic G. 1996. Harvey J, ed. 
Winetitles: Adelaide. p.245.

81. Nicolau C. and Cudd A. 1989. Liposomes as carriers of DNA. Crit. Rev. Therap. Drug Carrier Systems. 6: 239-271.

82. Nolte RT and Atkinson D. 1992.Biophys. 63:1221-1239.

83. Osborne JC and Brewer Jr. 1992. Ann. N.Y. Acad. Sci. 348: 104-121

84. Papahadjopoulos D, Post G, Vail WJ and Biedler JL. 1976. Use of lipid vesicles as carriers to introduce Actinomycin D into resistant tumor cells. Cancer Res. 36: 2988-2994.

85. Pinker RJ, Lin L, Rose GD and Kallenbach NR. 1990. Protein Science. 2: 1099.

86. Rose JK, Buoncore L and Whitt MA.1991. A new cationic liposome reagent mediating nearly quantitative transfection of animal cells. Biotechniques. 10: 520-525.

87. Rosenberg M and Kopelman IJ. 1983. Food Science Technology. 2: 142-143

88. Segrest JP, Jackson RL and Morrisett JD. 1974. FEBS Lett. 38: 247-253.

89. Sharon N.Glycoproteins now and then: a personal account.1998. Acta Anat (Basel). 161(14): 7-17.

90. Segrest JP, Garber DW, Brouillette CG, Harvey SC and Anantharamaiah GM. 1994. Adv. Protein Chem. 45: 303-369.

91. Sharon $\mathrm{N}$ and Lis H. 2002. How proteins bind carbohydrates: lessons from legume lectins. $J$ Agric Food Chem. 50(22): 6586-6591.

92. Schiffer M, Edmunson AB. 1967. Biophys. 7:121-125

93. Szoka F. and Papahadjopoulos D. 1978. Proc. Natl. Acad. Sci. USA 75:4194-4198

94. Smith LC, Pownall HJ and Gotto AM. Jr. 1978. Annu. Rev. Biochem. 47:751-777.

95. Sou1ages JL, Wells MA. 1994. Adv. Protein Chem. 45: 371-415.

96. Szoka F and Papahadjopoulos D. 1980. Annual Review of Biophysics and Bioengineering. 9: 467-508.

97. Smith T .1996. Liposomes in Cell Culture. In: Baianu IC, Pessen H and Kumosinski TF, eds. Physical Chemistry of Food Processes. Vol 2. New York: Van Nostrand Reinhold. p. 554-587.

98. Taylor AH. 1983. Food Flavour. Ingredients Packag. Process. 5: 48-52

99. Toenniessen GH, Toole J and DeVires J. 2003. Advances in plant biotechnology and its adoption in developing countries. Current Opinion in Plant Biology. 6:191-198.

100. Vazquez S R, Kuo D Z, Botsitis CM, Hardy LW, Lew RA and Humphreys RE. 1992. J. Biol. Chem. 267: 7406-7410.

101. Verhasselt P., Poncelet F, Vits K, Van Gool, A. and Vanderleyden, J.1989. Cloning and expression of a Clostridium alpha-amylase gene in Escherichia coli. FEMS Microbiol. Lett. 59: 
135-140.

102. Weiner SJ, Kollman PA, Case DA, Singh U C, Ghio C, Alagona G, Profeta S, Weiner PK. 1984. J. American. Chemical Society.106: 765-784.

103.Weiner SJ, Kollman PA, Nguyen DT, Case DA. 1986. J. Comput. Chem. 7: 230-252.

104.Weisgraber KH.1994. Adv. Protein Chem. 45: 249-302.

105.Wilson C, Wardell MR, Weisgraber KH, Mah1ey RW and Agard DA.1991. Science. 252: 1817-1822.

106. Witter L.1996. Immobilized Microbial Cells. In: Baianu IC, Pessen H and Kumosinski TF, eds. Physical Chemistry of Food Processes. Vol 2. New York: Van Nostrand Reinhold. p. 475486.

107. Wuthrich K. 1986. NMR of Proteins and Nucleic Acids. John Wiley \& Sons, Inc.: New York.

108. Zappe H, Jones WA and Woods DR.1987. Cloning and expression of xylanase gene from Clostridium acetobutylicum $\mathbf{P 2 6}$ in Escherichia coli. Appl. Microbiol. Biotechnol. 27: 57-63. 